\title{
Água potável com desumidificação do ar e energia solar: adaptação ao stress hídrico no RS
}

\author{
Drinking water with air dehumidification and solar energy: \\ adaptation to drought stress in RS
Eliezer Henker'1, Fernanda Sartori Rodrigues², Bárbara Meier da Costa ${ }^{3}$, Jonas Kearcher', Ênio Leandro Machado ${ }^{4}$

口

\section{RESUMO}

O Rio Grande do Sul apresenta uma média de precipitações entre 1200 e 2400 mm de chuvas por ano. No entanto, as mudanças climáticas estão concentrando essas chuvas nas regiões sul e leste do estado. Como consequência, desde os últimos 10 anos há situações de extremo stress hídrico para abastecimento de água com potabilidade nas regiões oeste e norte. Entretanto, essas regiões mantêm níveis de umidade relativa mínima superiores a $60 \%$. Assim sendo, esta pesquisa investigou o uso do sistema Peltier em configuração compacta com fotodesinfecção para obtenção de água potável. O módulo foi formado por uma caixa de poliestireno expandido, pastilha Peltier, dissipadores de alumínio, ventilador, reservatório plástico e funil. A unidade de armazenamento de água foi composta por tubo de quartzo $(60 \times 700 \mathrm{~mm})$ com passagem de raios UV (lâmpada germicida de $8 \mathrm{~W}$ ) e bomba hidráulica responsável pela retirada de toda a água do sistema de armazenamento. A condensação induzida, com umidade relativa de $80 \%$, gerou até $2,6 \mathrm{~L} \cdot \mathrm{m}^{2} . \mathrm{h}^{-1}$ e o consumo energético ficou em torno de 7,92 kWh para cada litro de água coletada.

Palavras-chave: Peltier; umidade relativa; desinfecção.

\begin{abstract}
The state of Rio Grande do Sul, Brazil, has an average rainfall between 1200-2400 mm per year. However, climate change is concentrating these rains in the south and east of the state. As a consequence, since the last 10 years there are situations of extreme water stress for water potability in the western and northern regions. However, these regions maintain minimum relative humidity levels above $60 \%$. Therefore, this study investigated the use of Peltier system in compact configuration with photo disinfection to obtain drinking water. The module consisted of a box of expanded polystyrene, Peltier chip, aluminum heatsinks, fans, plastic container and funnel. The storage unit was comprised of a water quartz tube $(60 \times 700 \mathrm{~mm})$ with the passage of UV radiation (germicidal lamp of $8 \mathrm{~W}$ ) and the hydraulic pump responsible for removal of all water from the storage system. The condensation induced with relative humidity of $80 \%$ generated up to $2.6 \mathrm{~L} . \mathrm{m}^{-2} . \mathrm{h}^{-1}$ and the energy consumption was about $7.92 \mathrm{kWh}$ per liter of water collected.
\end{abstract}

Keywords: Peltier; relative humidity; disinfection.

\section{INTRODUÇÃO}

O Rio Grande do Sul apresenta uma média de precipitações entre 1200 e 2400 mm de chuvas por ano. No entanto, as mudanças climáticas estão concentrando essas chuvas nas regiões sul e leste do estado. Como consequência, desde os últimos 10 anos há situações de extremo stress hídrico para abastecimento de água com potabilidade nas regiões oeste e norte. Reportagens demonstram as famílias com agravantes no mínimo comparáveis às regiões semiáridas mais críticas do Brasil.

Todas as medidas que podem minimizar o stress hídrico deverão incluir educação, saneamento ecológico (ECOSAN) e preservação/recuperação das fontes de água potável (BOHRER, 1995; DESIDERI; PROIETTI;
SDRINGOLA, 2009). É claro que todos esses aspectos dos impactos antropogênicos nos ecossistemas globais são agravados por mudanças climáticas. Secas e irregularidades nas chuvas são ocorrências em regiões tradicionalmente isentas de problemas com potenciais hídricos, como o exemplo da região do Vale do Rio Pardo, no Rio Grande do Sul.

Neste sentido, além das medidas de sustentabilidade ambiental e atenuação dos efeitos climáticos, novas formas de potabilização alternativa de água serão medidas de apoio para atenuação do stress hídrico (MACHADO et al., 2003).

Entretanto, outro enfoque de pesquisa deve ser considerado: agregar a potabilização mais limpa com fontes alternativas de água potável

'Mestre em Tecnologia Ambiental pela Universidade de Santa Cruz do Sul (UNISC) - Santa Cruz do Sul (RS), Brasil.

${ }^{2}$ Acadêmica do Curso de Química Industrial da UNISC - Santa Cruz do Sul (RS), Brasil.

${ }^{3}$ Engenheira Ambiental pela UNISC - Santa Cruz do Sul (RS), Brasil.

${ }^{4}$ Doutor em Engenharia pela Universidade Federal do Rio Grande do Sul (UFRGS). Professor do Mestrado em Tecnologia Ambiental da UNISC - Santa Cruz do Sul (RS), Brasil.

Endereço para correspondência: Ênio Leandro Machado - Avenida Independência, 2293 - 96815-900 - Santa Cruz do Sul (RS), Brasil - E-mail: enio@unisc.br

Fonte de financiamento: Fundação de Amparo à Pesquisa do Estado do Rio Grande do Sul (FAPERGS).

Recebido: 04/12/12 - Aceito: 07/01/14 - Reg. ABES: 741 
(MORAES NETO; BARBOSA; ARAÚJO, 2007). Neste sentido, a desumidificação do ar poderá ser uma alternativa, pois mesmo em regiões secas há disponibilidade de umidade relativa de 15 g. $\mathrm{kg}^{-1}$.

O desafio de outros pesquisadores explorou o aumento da área superficial do trocador de calor capaz de gerar $30 \mathrm{~L} \cdot \mathrm{m}^{-2}$. dia ${ }^{-1} \mathrm{com}$ placas de alumínio com temperatura de $0^{\circ} \mathrm{C}$ (MUSELLI et al., 2006).

Habeebullah (2009) empregou bobinas de refrigeração semelhantes às empregadas em aparelhos de climatização. Para umidade relativa típica da região da Arábia Saudita (entre 30 e 70\%) foram obtidos $17,6 \mathrm{~kg} \cdot \mathrm{m}^{-2}$.dia ${ }^{-1}$ para uma velocidade de ar de 2,25 m.s. ${ }^{-1}$. Na mesma pesquisa, em intervalo de investigação entre agosto e fevereiro foram obtidos valores médios de $401 \mathrm{~kg} \cdot \mathrm{m}^{-2}$.mês ${ }^{-1}$.

Esam \& Horr (2011) investigaram a obtenção de água potável através das unidades de refrigeração de ar condicionado amplamente utilizadas em instalações residenciais, comerciais e industriais na região do Golfo. Os resultados demonstraram a produção de 7,2 L.kW-1 dia $^{-1}$ de água, o que viabiliza a gestão desse recurso, tendo em vista que a precipitação na região fica em torno de $80 \mathrm{~mm}$ anuais.

Experimentos para geração de condensados aquosos a partir da umidade do ar estão crescendo no interesse de alguns pesquisadores (KAJIYAMA, 1974; SOFRATA, 1981; MICHAEL, 1996; HALL, 1996; SULTAN, 2002; HILDBRAND et al., 2004; KABEEL; 2004). Silva e Souza (2009) investigaram a taxa de produção, por metro quadrado de área resfriada, para as condições de regiões semiáridas do nordeste brasileiro. Os resultados são animadores, estabelecendo valores de 1,23 L.h.-1. $\mathrm{m}^{-2}$ com consumo de energia de $0,75 \mathrm{~kW} \cdot \mathrm{h}^{-1}$.

As publicações de Vanek (1996) e Moreno-Quintanar, Riveira e Best (2011) estabeleceram referências de proposição e continuidade para a unidade desumidificadora. Embora o maior problema dos sistemas seja a manutenção dos vasos de pressão (pressão máxima de 13 atm), há o aspecto de uso exclusivo de energia solar.

A partir dessas dificuldades operacionais, surgiu a proposta do sistema Peltier (LUKASIEVICZ; SILVA; BAZZO, 2010), estabelecendo um sistema compacto com lâmpadas germicidas visando desinfecção do ar úmido e da fração de água condensada.

A proposição de sistema com potencial de obtenção de água potável a partir da umidade do ar foi investigada neste trabalho, envolvendo determinação das características climáticas da região do Vale do Rio Pardo, Rio Grande do Sul, e desenvolvimento de sistema desumidificador compacto com acoplamento de desinfecção via $\mathrm{UV} / \mathrm{O}_{3}, \mathrm{com} \mathrm{O}_{3}$ gerado in situ.

\section{METODOLOGIA}

\section{Caracterização dos dados climatológicos}

O levantamento de dados climatológicos entre os anos de 2005 e 2011 foi realizado via dados disponíveis na Estação Meteorológica do Campus Central da Universidade de Santa Cruz do Sul (UNISC), vinculada ao Departamento de Engenharia, Arquitetura e Ciências Agrárias. Através dos dados coletados foi elaborado um quadro sintetizando os dados climatológicos da região.

Do Sistema de Monitoramento Agrometeorológico (AGRITEMPO) foram coletados os dados da Estação Meteorológica Automática do Instituto Nacional de Meteorologia (INMET) de Rio Pardo no intervalo de 01/01/2008 a 01/12/2011.

Os dados climatológicos coletados dos períodos foram: precipitação média mensal e anual, temperatura média mínima mensal, temperatura média mensal, temperatura média máxima mensal e umidade relativa média mensal.

Junto ao Comitê de Gerenciamento da Bacia Hidrográfica do Rio Pardo foram pesquisados os boletins informativos de 2005, onde se encontra o texto referente à precipitação pluviométrica de Santa Cruz do Sul do período de 1914 a 1968.

\section{Ensaios de desumidificação em escala de bancada}

Após caracterização dos dados climatológicos foi considerada a etapa de desumidificação do ar para obtenção de água potável. A Figura 1 demonstra o arranjo experimental para uso das garrafas de polietileno tereftalato (PET) de $2 \mathrm{~L}$ com área superficial de $0,08853 \mathrm{~m}^{2}$ contendo no seu interior água congelada.

As garrafas foram fixadas com uma linha em uma barra metálica permanecendo com a tampa para cima a fim de facilitar a fixação e eliminar o uso de acessórios. Todos os ensaios foram realizados empregando duas garrafas.

Antes do congelamento, as garrafas foram lavadas com detergente, água, álcool e água deionizada e então dispostas no freezer do refrigerador. O período de congelamento das garrafas foi de 12 horas. Para o congelamento foi empregado um refrigerador tipo Duplex com consumo de $40 \mathrm{kWh}$. Ao serem retiradas do freezer, as garrafas foram lavadas com água deionizada.

Cones de Imhoff e suporte foram empregados para armazenar a amostra durante o experimento.

Com a unidade de bancada foram verificados parâmetros operacionais e de controle do sistema. Os parâmetros de controle envolveram: velocidade do ar admitido para desumidificação, umidade relativa, temperatura ambiente e temperatura de superfície e taxa de desumidificação. A coleta de dados foi realizada de hora em hora.

Os instrumentos de medição empregados foram: termômetro FLUKE 62 MINI IR Thermometer; anemômetro INSTRUTHERM termo-higro-anemômetro luxímetro digital portátil Modelo THAL -300.

A fim de simular diferentes velocidades de ar, foram empregados um mini ventilador de 12 V, 0,25 A e $3 \mathrm{~W}$ e um circulador de ar doméstico médio $220 \mathrm{~V}, 0,32 \mathrm{~A}$ e $70 \mathrm{~W}$. 


\section{Análise da qualidade da água}

A água obtida por desumidificação foi caracterizada com os parâmetros de matéria orgânica, $\mathrm{pH}$, turbidez, condutividade, coliformes totais e Escherichia coli. Os parâmetros físico-químicos da água coletada foram analisados no Laboratório de Tecnologia e Tratamento de Águas e Efluentes (LATTAE) da UNISC. Todos os procedimentos foram executados conforme o Standard Methods for The Examination of Water and Wastewater (APHA, 2005).

\section{Configuração do sistema de desumidificação para geração de água potável}

A configuração da fonte alternativa de água potável estudada envolveu unidade de fotodesinfecção inicial e unidade trocadora de calor com base na célula de Peltier.

A célula termoelétrica de efeito Peltier foi dividida em cinco partes: fonte de alimentação; painel elétrico; unidade de captação de ar e esterilização de ar e água; unidade de armazenamento de água e módulo de condensação. A Figura 1 apresenta o sistema compacto concebido.

O equipamento é abastecido por uma fonte chaveada para PC bivolt 110/220 V de $400 \mathrm{~W}$ e 6A. Internamente, uma lâmpada germicida UV de
$254 \mathrm{~nm}$ foi posicionada a fim de desinfetar o ar da câmara. Lâmpadas UV são capazes de gerar ozônio em pequenas ou grandes quantidades conforme suas características construtivas. O ozônio gerado pelas lâmpadas circulará pelos dutos do sistema proporcionando um ambiente desinfetado na estrutura interna do equipamento.

A unidade de armazenamento de água é formada por um tubo de quartzo, o qual permite a passagem de raios UV. Conectado ao tubo de quartzo está a bomba hidráulica responsável pela retirada de toda a água do sistema de armazenamento.

A fim de intensificar a desinfecção por UV, refletores de alumínio polido foram posicionados em torno do tubo de armazenamento de água.

A placa termoelétrica $(62 \times 62 \mathrm{~mm}, 120 \mathrm{~W}, 15,4 \mathrm{~V}, 14 \mathrm{~A})$ está situada no módulo de condensação. O módulo é formado por uma caixa de Poliestireno Expandido (EPS), pastilha Peltier, dissipadores de alumínio, ventilador, reservatório plástico e funil.

A pastilha Peltier é inserida na tampa da caixa de EPS que serve de isolamento térmico das faces quente e fria da pastilha. Na parte superior da tampa é posicionado um dissipador de alumínio disposto em contato com a parte quente da pastilha. Sobre o mesmo são fixados dois ventiladores que auxiliam na dissipação do calor do lado quente.

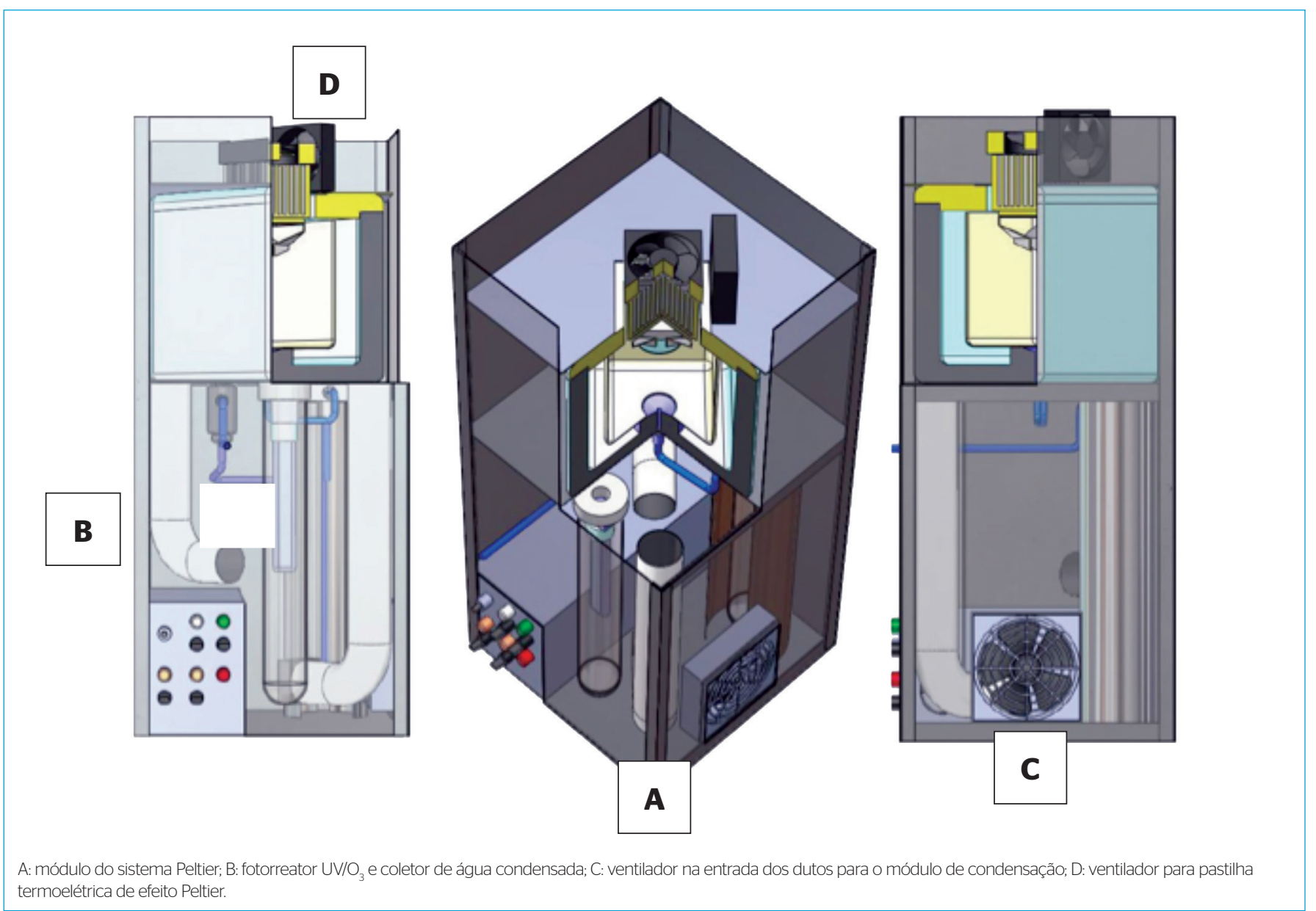

Figura 1 - Sistema Peltier - Projeto do sistema empregando pastilha termoelétrica de efeito Peltier. 
Internamente, outro dissipador de alumínio é fixado em contato com o lado frio da pastilha. Nesse elemento ocorre a condensação da água. A água condensada é armazenada na unidade de armazenamento formada pelo tubo de quartzo.

No painel elétrico é possível ligar e desligar o equipamento, controlar o acionamento de ventiladores que auxiliarão na formação de condensado, acionar a bomba hidráulica para retirada de água do sistema, controlar a velocidade do temporizador e acionar a lâmpada UV para desinfecção da água. Todos os componentes possuem luzes identificadoras de funcionamento.

A unidade de captação e esterilização de ar e água foi formada por uma câmara situada na parte inferior do equipamento. Um ventilador traseiro faz a coleta de ar para o sistema. Outro é posicionado na entrada dos dutos que seguem para o módulo de condensação.

\section{RESULTADOS E DISCUSSÃO}

\section{Aspectos climatológicos}

A temperatura de ponto de orvalho é um fator chave no dimensionamento de sistemas de desumidificação para obtenção de água através da condensação. Os sistemas propostos idealizados buscam, em sua concepção, apresentar a superfície de condensação com temperatura abaixo do ponto de orvalho, minimizando assim problemas de ausência de condensação.

Considerando que as precipitações anuais são satisfatórias na região do Vale do Rio Pardo (HOPPE, 2005) outros dados merecem destaque: umidade relativa do ar média anual entre 65 e $85 \%$; faixa de temperatura média mínima e máxima se concentrando entre 5 e $35^{\circ} \mathrm{C}$; temperatura do ponto de orvalho entre -1 e $32^{\circ} \mathrm{C}$. Sob essa perspectiva, o regime de trabalho dos sistemas desumidificadores propostos tem em sua superfície de condensação temperaturas abaixo do ponto de orvalho, considerando a umidade relativa do ar e a temperatura ambiente no local do experimento.

A partir da tabulação dos dados da estação meteorológica da UNISC foi possível a elaboração da Figura 2, que demonstra as precipitações médias mensais entre os anos de 2005 e 2011. As precipitações dependem de frentes frias, enquanto que a umidade relativa é inversamente correlacionada com temperatura.

As curvas de temperatura média máxima (Figura 3) e mínima (Figura 4) do período demonstram a normalidade dos ciclos das estações do ano - verão/outono/inverno/primavera. A Figura 5 demonstra a variação da umidade relativa média durante o ano e informa que no período do inverno, onde as temperaturas são mais baixas, a umidade relativa do ar é maior.

Sistemas desumidificadores que interpretam estes dados de entrada, tais como temperatura da face fria, temperatura ambiente e umidade relativa, podem economizar energia.

\section{Sistema de desumidificação para geração de água potável com uso de célula termoelétrica}

Estudos preliminares apontaram para o emprego de Pulse-Width Modulation (PWM) para controlar a corrente elétrica nas pastilhas Peltier. Eessa tecnologia é empregada para variar a entrega de potência em determinada carga fazendo com que haja um controle de corrente elétrica ora ligada, ora desligada, provocando uma queda de tensão muito baixa no circuito.

Esse sistema permite controlar o fluxo de corrente através de um potenciômetro ou microcontrolador. Também é possível a redução do consumo energético tendo em vista o fornecimento de corrente elétrica ser através de pulsos, e não continuamente.

O módulo PWM deve permitir a circulação de corrente de $14 \mathrm{~A}$ com base no modelo de célula termoelétrica empregada.

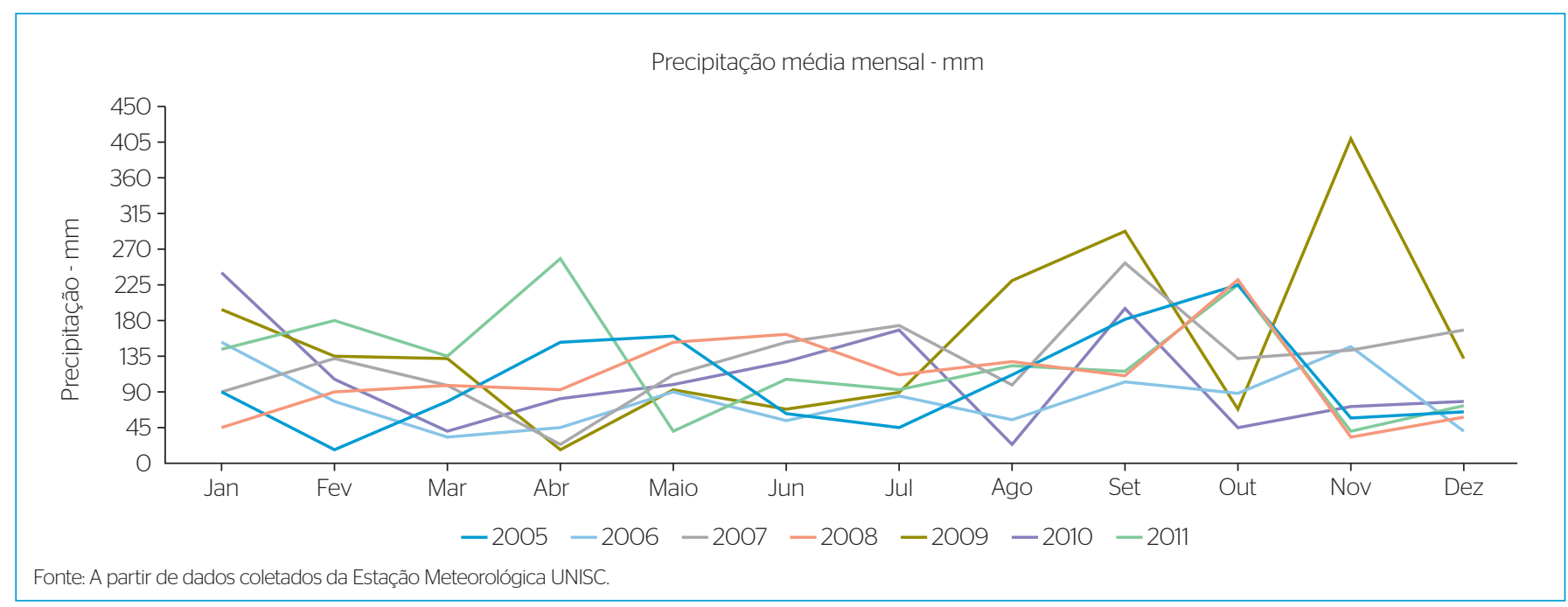

Figura 2 - Precipitação média mensal do Campus Universitário de Santa Cruz do Sul (UNISC) no período de janeiro de 2005 a junho de 2011. 


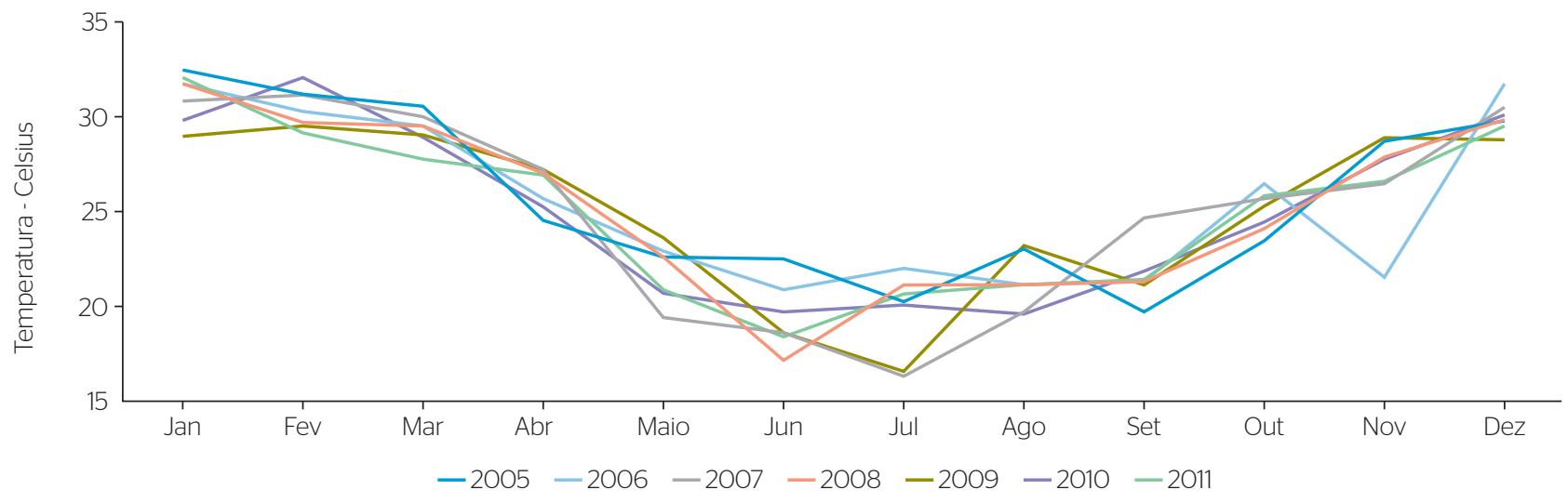

Fonte: A partir de dados coletados da Estação Meteorológica UNISC.

Figura 3 - Temperatura máxima média do Campus Universitário de Santa Cruz do Sul (UNISC) no período de janeiro de 2005 a junho de 2011.

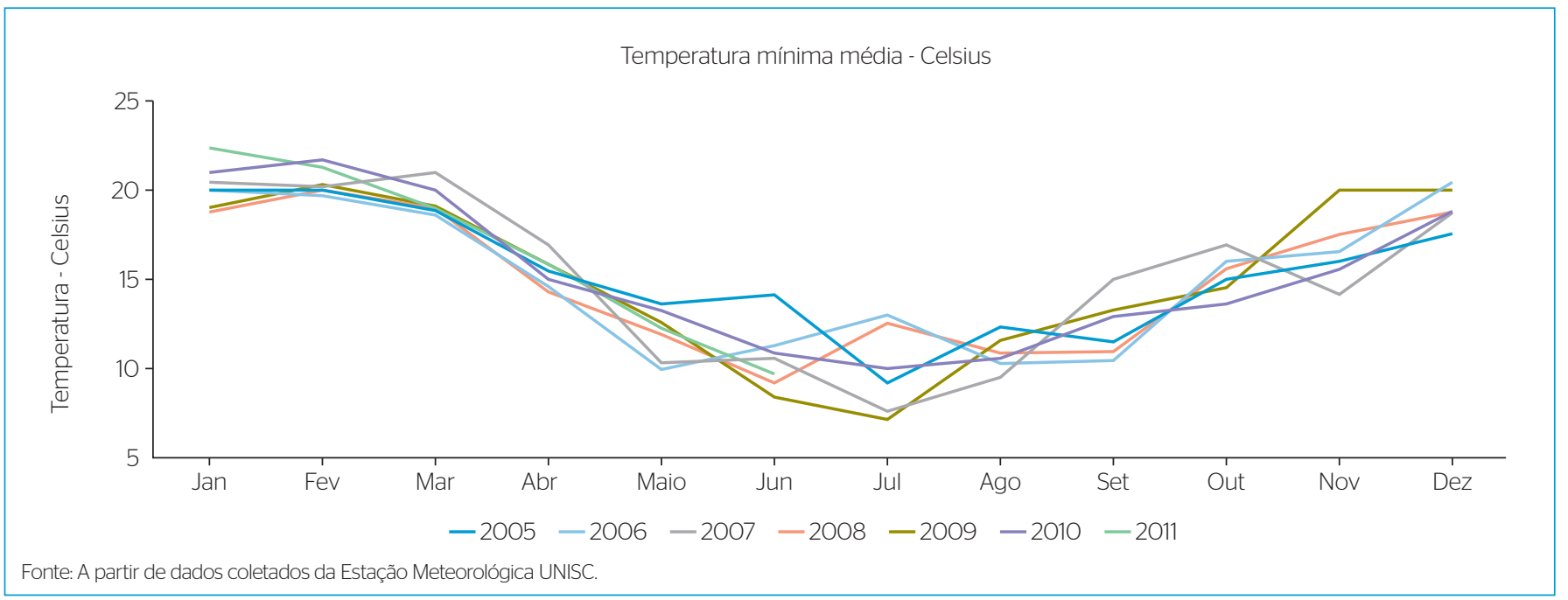

Figura 4 - Temperatura mínima média do Campus Universitário de Santa Cruz do Sul (UNISC) no período de janeiro de 2005 a junho de 2011.

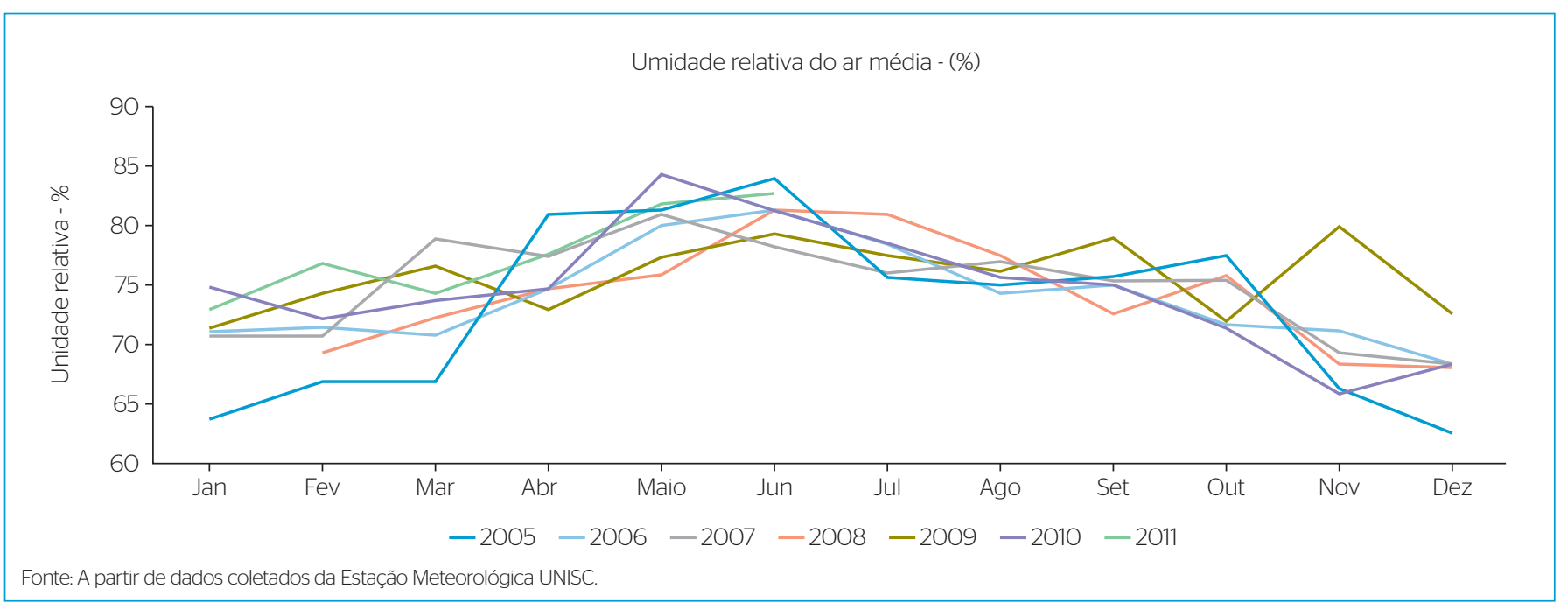

Figura 5 - Umidade relativa do ar média do Campus Universitário de Santa Cruz do Sul (UNISC) no período de janeiro de 2005 a junho de 2011. 
Entretanto, a elaboração de um sistema PWM capaz de suportar a carga de $120 \mathrm{~W}$ se tornou um elemento especial de difícil construção para o protótipo; um temporizador de 1 a 15 segundos para controlar o ligamento e desligamento da célula foi utilizado no experimento. O teste experimental empregando o protótipo permitiu testar o sistema com uma ou duas células termoelétricas. O objetivo do teste foi verificar a relação tensão/corrente, o consumo e possível formação de orvalho do sistema.

Aplicou-se a tensão de 1 a $8 \mathrm{~V}$ na célula termoelétrica, verificando assim a intensidade de corrente consumida pelo sistema. A configuração aplicada foi de duas pastilhas sobrepostas. Os instrumentos empregados foram: uma fonte de tensão de corrente contínua, modelo DC Instrutherm FA2030, com capacidade de 30 A a 24 V; um multímetro digital modelo Minipa ET2037; e um anemômetro Instrutherm termo-higro-anemômetro luxímetro digital portátil Modelo THAL -300.

Com os dados coletados foi possível verificar a intensidade de corrente para cada volt de tensão fornecida ao sistema e calcular a potência elétrica consumida bem como o consumo em $\mathrm{kWh}$.

O sistema testado não apresentou formação considerável de orvalho, somente uma superfície levemente úmida. A área de condensação neste caso era de $0,25 \mathrm{~m}^{2}$ e a umidade relativa do ar era de $80 \%$. Nesse experimento não foram realizadas medições de temperatura no lado frio da pastilha devido à reduzida condensação presenciada.

A fim de verificar a temperatura da superfície fria da pastilha termoelétrica, um sistema foi montado sobre a bancada com duas pastilhas sobrepostas. No lado quente foi fixado um dissipador de alumínio e dois ventiladores. Os ventiladores foram acionados por uma fonte de tensão de corrente contínua de $12 \mathrm{~V}$ e $2 \mathrm{~A}$, cada ventilador com potência de $3 \mathrm{~W}$.

O experimento foi limitado a uma tensão de $8 \mathrm{~V}$ devido à capacidade do termômetro em medir temperaturas inferiores a $-15^{\circ} \mathrm{C}$. O termômetro empregado foi o termômetro digital marca/modelo Minipa MT-360. De acordo com as especificações técnicas da pastilha termoelétrica, o gradiente de temperatura entre a face quente e fria é de $67^{\circ} \mathrm{C}$ para um $\mathrm{I}_{\text {máx }}$ de $14 \mathrm{~A}$ e um $\mathrm{V}_{\text {máx }}$ de 15,4 V. Nessas condições, mantendo a temperatura do lado quente $\mathrm{em} 40^{\circ} \mathrm{C}$, teoricamente chegar-se-ia a uma temperatura de $-27^{\circ} \mathrm{C}$ no lado frio da pastilha.

O consumo energético total do sistema, empregando $8 \mathrm{~V}$ e 10,4 A é de cerca de $0,0892 \mathrm{kWh}$, considerando os ventiladores de arrefecimento; a área de condensação é somente a área do lado frio da pastilha, cerca de $3,844 \times 10^{-3} \mathrm{~m}^{2}$.

Nos experimentos com pastilhas termoelétricas de dimensões menores, $40 \times 40 \mathrm{~mm}$, o consumo máximo do sistema foi de $35 \times 10^{-3} \mathrm{kWh}$. Nesses testes com somente uma pastilha, não foi necessário o emprego de ventilador para arrefecimento, o dissipador de alumínio foi suficiente para a temperatura do lado quente não ultrapassar a temperatura máxima de trabalho da pastilha. No lado frio houve formação de condensado aquoso.
A Tabela 1 demonstra os dados coletados nas duas configurações propostax nos experimentos.

A pastilha $40 \times 40 \mathrm{~mm}$ tem uma área de $1,6 \times 10^{-3} \mathrm{~m}^{2}$. Para a montagem do sistema com pastilhas termoelétricas sobrepostas, o consumo de energia foi de $81 \times 10^{-3} \mathrm{kWh}$, considerando um ventilador de $12 \mathrm{~V}$ e 0,25 A para o arrefecimento. Nesse experimento, houve a formação de gelo e condensado aquoso no lado frio da pastilha.

O sistema projetado (Figura 1) para geração de água potável com o emprego de células termoelétricas apresentou um custo relativamente baixo, em torno de R\$1.200,00 com a unidade de desinfecção. É possível construir um sistema simplificado sem a unidade de desinfecção ao custo de $\mathrm{R} \$ 400,00$.

Um amplo estudo experimental de configurações empregando pastilhas Peltier foi realizado. Também foram definidas as propriedades termodinâmicas que apresentaram resultados satisfatórios na obtenção de água. As pastilhas sobrepostas de 62 x $62 \mathrm{~mm}$ foram empregadas no equipamento.

No equipamento foram inseridos dois ventiladores para obter uma ventilação satisfatória no lado frio da pastilha e formação do condensado aquoso. O equipamento permite o acionamento individual dos ventiladores, podendo assim variar a velocidade do vento na câmara de condensação. De acordo com os testes realizados, é necessário acionar os dois ventiladores para obter uma maior formação de condensado aquoso

Em relação à área de condensação do desumidificador, foi considerada a área da pastilha termoelétrica no lado frio, de cerca de $3,844 \times 10^{-3} \mathrm{~m}^{2}$. A tensão destinada às pastilhas foi de $10 \mathrm{~V}$ e a intensidade de corrente de 6,6 A.

O equipamento fornece tensões de 10, 12 e 220 V. Para a tensão de $12 \mathrm{~V}$, a potência total foi de $25 \mathrm{~W}$ (ventiladores e lâmpadas

Tabela 1 - Medições realizadas em bancada com pastilha 40 × 40 mm.

\begin{tabular}{l|c|c|c} 
Tensão (V) & Corrente (A) & Potência (W) & Consumo kWh \\
\hline 1 & 0,2 & 0,2 & 0,0002 \\
\hline 2 & 0,6 & 1,2 & 0,0012 \\
\hline 3 & 1,0 & 3,0 & 0,0030 \\
\hline 4 & 1,4 & 5,6 & 0,0056 \\
\hline 5 & 1,8 & 9,0 & 0,0090 \\
\hline 6 & 2,2 & 13,2 & 0,0132 \\
\hline 7 & 2,5 & 17,5 & 0,0175 \\
\hline 8 & 2,9 & 23,2 & 0,0232 \\
\hline 9 & 3,2 & 28,8 & 0,0288 \\
\hline 10 & 3,5 & 35,0 & 0,0350 \\
\hline
\end{tabular}


indicadoras), quando acionada a bomba hidráulica, há um acréscimo de $24 \mathrm{~W}$; para a tensão de $220 \mathrm{~V}$ a potência total foi de $11 \mathrm{~W}$ (lâmpada germicida e lâmpadas indicadoras).

O Quadro 1 relaciona os dados coletados empregando o sistema de desumidificação com célula termoelétrica. Aparentemente, os melhores resultados demonstram que o volume de água coletado pode chegar a $2,6 \mathrm{~L} \mathrm{~m}^{-2} \cdot \mathrm{h}^{-1}$ com uma umidade relativa do ar de $80 \%$ e vento na faixa de $7 \mathrm{~km} \cdot \mathrm{h}^{-1}$, porém, o consumo energético pode chega a 7,92 kWh para cada litro de condensado aquoso nestas condições.

Observa-se que o controle da temperatura do ponto de orvalho é um fator determinante para a redução do consumo energético, tendo em vista que durante os experimentos não houve esse controle e a célula esteve sempre com a temperatura do lado frio em torno de $-13^{\circ} \mathrm{C}$, bem abaixo da temperatura de ponto de orvalho, que era de aproximadamente $21^{\circ} \mathrm{C}$. Em umidade relativa de $60 \%$ e temperatura ambiente de $29,9^{\circ} \mathrm{C}$, a produção de volume de água fica em torno de $1,39 \mathrm{~L} \cdot \mathrm{m}^{-2} \cdot \mathrm{h}^{-1}$

Tabela 2 - Parâmetros de caracterização da água obtida com o sistema Peltier.

\begin{tabular}{l|c} 
Parâmetros & Valores \\
\hline Coliformes totais & Ausentes \\
\hline Escherichia coli & Ausentes \\
\hline $\mathrm{pH}$ & 7,3 \\
\hline Oxigênio consumido $\left(\mathrm{mg}^{\mathrm{L}} \mathrm{L}^{-1}\right)$ & 3,5 \\
\hline Turbidez $(\mathrm{UT})$ & 0,4 \\
\hline Condutividade $\left(\mu{\left.\mathrm{S} . \mathrm{cm}^{-1}\right)}^{-1}\right)$ & 30 \\
\hline
\end{tabular}

com um consumo energético de 12,51 kWh. Esse valor é bem superior quando comparado aos dados de Silva e Souza (2009), os quais, como já citados, obtiveram desumidificação de $1,23 \mathrm{~L} \cdot \mathrm{h}^{-1} \cdot \mathrm{m}^{-2}$ com consumo de energia de 0,75 kWh envolvendo garrafas PET de 2,5 L com área superficial de $0,1 \mathrm{~m}^{2}$.

A qualidade da água obtida com a aplicação do sistema Peltier pode ser observada na Tabela 2. Parâmetros mais críticos da qualidade da água foram selecionados para caracterização.

Assim sendo, a proposição do sistema Peltier é alternativa, compacta e com consumo energético empregável para períodos de carência de água em regiões críticas quanto ao abastecimento

\section{CONCLUSÕES}

A concepção do sistema desumidificador com uso de célula termoelétrica procurou empregar materiais de baixo custo e facilmente aceitos no mercado de recicláveis. Sua construção emprega materiais como alumínio, aço, plásticos diversos, cobre, placas de circuito eletrônicos, componentes eletrônicos e lâmpadas.

Os custos do projeto empregando pastilhas Peltier ficaram em torno de R \$1.200,00 com a unidade de desinfecção. É possível construir um sistema simplificado sem a unidade de desinfecção ao custo de R $\$ 400,00$.

A pastilha termoelétrica tem uma vida útil longa. Testes de qualidade de alguns fornecedores indicam mais de mil horas de trabalho sem interrupção e 5 mil ciclos de ligamento e desligamento. Segundo eles, as pastilhas podem durar cerca de $200 \mathrm{mil}$ a 300 mil horas se observados os requisitos técnicos necessários.

Quadro 1 - Dados coletados empregando o sistema de desumidificação com célula termoelétrica.

\begin{tabular}{|c|c|c|c|c|c|c|}
\hline Dados & $\begin{array}{c}\text { Coleta } \\
1\end{array}$ & $\begin{array}{c}\text { Coleta } \\
2\end{array}$ & $\begin{array}{c}\text { Coleta } \\
3\end{array}$ & $\begin{array}{c}\text { Coleta } \\
4\end{array}$ & $\begin{array}{l}\text { Coleta } \\
5\end{array}$ & $\begin{array}{l}\text { Coleta } \\
\quad 6\end{array}$ \\
\hline Tempo de coleta (h) & 2 & 8 & 2 & 3 & 6 & 12 \\
\hline Volume total coletado (L) & 0,020 & 0,041 & 0,008 & 0,010 & 0,032 & 0,050 \\
\hline Volume total coletado por hora (L.h'-1) & 0,01000 & 0,00513 & 0,00400 & 0,00333 & 0,00533 & 0,00417 \\
\hline Temperatura ambiente $\left({ }^{\circ} \mathrm{C}\right)$ & 25,0 & 30,7 & 27,3 & 31,7 & 28,9 & 29,3 \\
\hline Temperatura do ponto de orvalho $\left({ }^{\circ} \mathrm{C}\right)$ & 21,0 & 20,6 & 21,0 & 21,0 & 21,0 & 21,0 \\
\hline Umidade relativa (\%) & 80,0 & 59,5 & 70,0 & 55,0 & 60,0 & 63,0 \\
\hline Potência total (W) & 79,2 & 66,7 & 66,7 & 66,7 & 66,7 & 66,7 \\
\hline Consumo (kWh) & 0,0792 & 0,0667 & 0,0667 & 0,0667 & 0,0667 & 0,0667 \\
\hline $\begin{array}{l}\text { Velocidade do vento no } \\
\text { condensador }\left(\mathrm{km} \cdot \mathrm{h}^{-1}\right)\end{array}$ & 7,0 & 16,5 & 16,5 & 16,5 & 16,5 & 12,5 \\
\hline $\begin{array}{l}\text { Consumo teórico para } 1 \text { litro de } \\
\text { condensado aquoso ( } \mathrm{kWh})\end{array}$ & 7,92 & 13,01 & 16,68 & 20,01 & 12,51 & 16,01 \\
\hline $\begin{array}{l}\text { Produção teórica de condensado } \\
\text { aquoso da célula Peltier ( }\left(1 \mathrm{~m}^{2} . \mathrm{h}^{11}\right)\end{array}$ & 2,60 & 1,33 & 1,04 & 0,87 & 1,39 & 1,08 \\
\hline
\end{tabular}


A unidade de desinfecção presente no sistema pode ser empregada separadamente para submeter amostras de água à radiação UV. Para isso, basta verter água no módulo de condensação e retirá-la através da bomba hidráulica com a lâmpada ligada.

Empregando-se células termoelétricas de efeito Peltier é possível obter água potável a partir de superfícies refrigeradas. A produção de água com umidade relativa de $80 \%$ pode ser de até aproximadamente 2,6 L.m $\mathrm{m}^{-2} \cdot \mathrm{h}^{-1}$ e o consumo energético fica em torno de 7,92 $\mathrm{kWh}$ para cada litro de água coletada. Considerando que no período da noite e mo início da manhã as temperaturas são mais amenas e a umidade relativa do ar é mais elevada, é previsível um funcionamento eficiente de aproximadamente 15 horas para o equipamento.
Essa tecnologia pode contribuir para o desenvolvimento sustentável do planeta, incorporando fontes de energias renováveis em sua operação. Estudos em semicondutores estão evoluindo e o uso de células termoelétricas já está amplamente difundido pela industria de bens de consumo para obtenção de superfícies frias.

De acordo com os testes parciais de potabilidade, a água coletada apresenta resultados favoráveis para o consumo humano. A fim de melhorar e garantir esses níveis, um sistema de filtração pode ser acrescentado.

Em casos extremos, tais como catástrofes naturais, acidentes, locais de difícil acesso e regiões áridas e semiáridas, a coleta de água através da condensação em superfícies frias pode ser uma ótima alternativa para obtenção de água potável.

\section{REFERÊNCIAS}

APHA - AMERICAN PUBLIC HEALTH ASSOCIATION. (2005) Standard Methods for the Examination of Water and Wastewater. 21 ed. Washington: APHA/AWWA/WEF.

BOHRER, M.B. (1995) Biomonitoramento das lagoas de tratamento terciário do sistema de tratamento dos efluentes líquidos industriais (SITEL) do pólo petroquímico do sul, Triunfo, RS, através da comunidade zooplanctônica. Tese (Doutorado em Ciências) - Universidade Federal de São Carlos, São Paulo. 469 p.

DESIDERI, U.; PROIETTI, S.; SDRINGOLA, P. (2009) Solar-powered cooling systems: technical and economic analysis on industrial refrigeration and air-conditioning applications. Applied Energy, v. 86, n. 9. p. 1376-1386.

ESAM, E. \& HORR, Y.A. (2001) Experimental investigations on water recovery from the atmosphere in arid humid regions. In: CIBSE Technical Symposium. Leicestern, UK: CIBSE.

HABEEBULLAH, B.A. (2009) Potential use of evaporator coils for water extraction in hot and humid areas. Desalination, v. 237, p. 330-345.

HALL, R.C. (1996) Theoretical calculations on the production of water from the atmosphere by absorption with subsequent recovery in a solar still. Solar Energy, v. 10, n. 1, p. 41-45.

HILDBRAND C.; DIND, P.; PONS, M.; BUCHTER, F. (2004) A new solar powered adsorption refrigerator with high performance. Solar Energy, v. 77, n. 3, p. $311-318$

HOPPE, M. (2005) Pluviometria em Santa Cruz do Sul. Boletim Informativo n011/Ano VII - Novembro/2005. Núcleo de Pesquisa e Extensão em Gerenciamento de Recursos Hídricos. Comitê de Gerenciamento da Bacia Hidrográfica do Rio Pardo - Comitê Pardo.

KABEEL, A.E. (2004) Application of sandy bed solar collector system for extraction of water from air. In: 8th International Water Technology Conference. Alexandria, Egypt: IWTC8, p. 231-249.
KAJIYAMA, Y. (1974) Air conditioning apparatus supplying potable water. French Patent 2.219.119.

LUKASIEVICZ, T:; SILVA, J.C.C; BAZZO, J.P. (2010) Caracterização dos parâmetros termoelétricos de um módulo Peltier. In: Anais do XV Seminário de Iniciação Científica e Tecnológica. Cornélio Procópio: SICITE.

MACHADO, E.L;; RODRIGUEZ LOPEZ, D.A.; VOESE, A.L.; LOURENÇO, A.E.F.N. (2003) Sistema de saneamento rural de baixo custo. In: Anais do 240 Congresso Brasileiro de Engenharia Sanitária e Ambiental. Joinville: CBESA.

MICHAEL C.L. (1996) Apparatus for producing filtered drinking water. United States Patent 5,517,829.

MORAES NETO, J.M.; BARBOSA, M.P.; ARAÚJO, A.E. (2007) Efeito dos eventos ENOS e das TSM na variação pluviométrica do semi-árido paraibano Revista Brasileira de Engenharia Agrícola e Ambiental, v. 11, n. 1, p. 61-66.

MORENO-QUINTANAR, G.; RIVERA, W.; BEST, R. (2011) Development of a solar intermittent refrigeration system for ice production. In: World Renewable Energy Congress. Linköping, Sweden.

MUSELLI, M.; BEYSENS, D.; MILIMOUK, I. (2006) A comparative study of two large radiative dew water condensers. Journal of Arid Environments, v. 70, n. 64, p. 54-76.

SILVA, G. \& SOUSA, F.A.S. (2009) Estudo da viabilidade da produção de água a partir do resfriamento do ar. Revista Brasileira de Engenharia Agrícola e Ambiental, v. 13, n. 5, p. 575-580.

SOFRATA, H. (1981) Non-conventional system for water collection In: Proceedings of the Second SOLERAS Workshop. Denver, Colorado. p. 71-87.

SULTAN, A. (2002) Absorption/regeneration non-conventional system for water extraction from atmospheric air. Renewable Energy, v. 29, p. 1515-1535.

VANEK, J. (1996) A solar ammonia absorption icemaker. Home Power, n. 53 , p. 19-23. 